\title{
Validation of Evaporative Cooling System using CFD Analysis
}

\author{
K.V. Vala ${ }^{1}$, Mahesh Makwana ${ }^{1}$ and Nukasani Sagarika ${ }^{2}$ \\ ${ }^{1}$ Department of Food Engineering, ${ }^{2}$ Department of Food Process Engineering, College of \\ $F P T \& B E, A A U$, Anand, India \\ *Corresponding author
}

Keywords

Refrigeration,

Evaporative

cooling, Simulation,

Validation,

Mathematical

modelling

Article Info

Accepted:

04 February 2019

Available Online:

10 March 2019

\begin{abstract}
A B S T R A C T
Evaporative cooling system is one of the cooling techniques, but the limitation is that cooling can be done up to wet bulb temperature only, so a study has been taken up to design, develop a two-stage evaporative cooling system. Cooling performance of twostage indirect/direct evaporative cooling system was experimentally investigated. For this purpose, a two-stage evaporative cooling experimental setup consisting of an indirect cooling stage (IDC) followed by a direct evaporative cooling stage (DEC) was designed, constructed and tested. The performance evaluation was done with respect to three different air supply velocities, three pad thicknesses and three water flow rates. The results showed that air velocity of $16.70 \mathrm{~m} / \mathrm{s}$, pad thickness of $200 \mathrm{~mm}$, and water flow rate of 5 $1 \mathrm{pm}$ were found to be the best operating parameters to obtain maximum reduction in air temperature between 22.10 to $25.80{ }^{\circ} \mathrm{C}$. Also, average relative humidity of air leaving was found to be in the range of $40.50 \%$ to $72.83 \%$. The obtained results were investigated for best operating parameters with a CFD code. The mathematical model, governing equations and the boundary conditions were implemented in the code and the calculated results were analyzed and compared with experimental data. The results were almost similar in both the cases and briefly described here under.
\end{abstract}

\section{Introduction}

Refrigerated van transportation is a wellestablished technology for maintaining the quality and prolonging the shelf-life of frozen and perishable products during transportation and is widely used for transporting high value produce (Chakraverty et al., 2003; Chaudhary, 2004; Sunmonu et al., 2014). But this system is energy intensive and expensive, involves high initial investment and requires uninterrupted supply of electricity. Because of these reasons, this system is not widely used in many tropical and sub-tropical countries for transport of fresh produce (Kumar et al., 2003; Nitipong and Sukum, 2011). It is also not affordable to small farmers, retailers and wholesalers (Samira et al., 2011). On the other hand evaporative cooling technique is simple, eco-friendly, zero energy and also most efficient method for cooling fruits and vegetables in dry and hot conditions (Mohmmad, 2013). The direct evaporative cooling has got the limitation for drop in air 
temperature, i.e. the maximum up to the wet bulb temperature of ambient air. Therefore, a systematic and scientific study was undertaken to design and develop a modified evaporative cooling system, called two-stage evaporative cooling system to improve the efficiency of evaporative cooling.

Computational fluid dynamics (CFD) is a simulation tool which uses numerical methods and algorithms to solve and analyze problems associated with fluid flow. It is the art of replacing the partial differential equations by a set of algebraic equations which can be solved using digital computers. It provides a qualitative (and sometimes even quantitative) prediction of fluid flows by means of mathematical modeling, numerical methods and software tools. Also, it enables the scientists and engineers to perform numerical experiments in a 'virtual flow laboratory' (Anon., 2018). Here are some CFD analysis works of physical systems which shows the potential use of CFD for analyzing fluid flow and heat transfer problems. Li et al., (2006) analyzed velocity and temperature distribution in the air-conditioned zone using CFD for combined evaporative cooling system with ceiling cooling, in which the evaporative cooling system handles the entire latent load and one part of the sensible loads, and the ceiling cooling system deals with the other part of sensible loads in the air-conditioned zone. Later in the year 2008, Sapounas et al., carried out simulation of the greenhouse equipped with a fan and pad evaporative cooling system using CFD considering both the external and internal climatic conditions. They validated the CFD results with the experimental data based on the greenhouse inside air temperature. They suggested that CFD is a suitable tool for the modelling and simulation of evaporative pads. Also Chen et al., (2014) used a CFD model to simulate the greenhouse adopting the fan-pad cooling system in summer and to find out the distribution of air velocity and temperature. Montazeri et al., (2015) presented a systematic evaluation of the Lagrangian-Eulerian approach for evaporative cooling provided by the use of a water spray system with a hollowcone nozzle configuration using CFD. They also analyzed impact of several physical parameters like inlet air temperature, inlet air humidity ratio, inlet air velocity, and inlet water temperature and inlet droplet size distribution for mist spray. Hence the main objective of the present study is to carry out experimental analysis of an EC system for selected boundary conditions followed by CFD analysis.

\section{Materials and Methods}

A two-stage evaporative cooling system consisting of direct cooling type (DEC) and indirect cooling type (IDC) systems was designed and fabricated (Fig. 1). In the arrangement indirect type cooling system was placed in first stage followed by direct type in second stage. Indirect type cooling system consists of a finned tube heat exchanger made of copper tube $(9.5 \mathrm{~mm}$ dia.), whereas direct type system made of wet-pad (CELdek pad, cross-fluted $45^{\circ} \mathrm{x} \quad 15^{\circ}$ ) type. In this arrangement, outside air passes through the indirect type where it gets sensibly cooled first and then same air is passes through direct type, where it becomes more cooled and humidified. Thus, air is cooled and humidified in this manner and send to storage chamber. For carrying of cooled air coming out from cooling system, a hollow duct was provided and fabricated. For uniform distribution of cooled air inside the storage chamber, a perforated vertical plate was provided on front side of the storage chamber and also perforated bottom channel was provided. The complete experimental unit is shown in Figure 2. Datta et al., (1987) have experimentally studied an 8.5 ton indirect-direct evaporative cooling system and reported that such a 
system provides a relief cooling rather than comfort cooling. The room could be maintained at $4-5{ }^{\circ} \mathrm{C}$ above the inlet wet bulb temperature using such a cooler. El-Dessouky et al., (2004) have carried out the performance analysis of two stage evaporative coolers and reported the efficiency of IDC (20-40\%) and DEC (63-93\%) systems when operated individually, whereas the efficiency of two stages IDC/DEC varied over a range of 90$120 \%$. Jain and Hindoliya (2012) designed and developed a regenerative type directindirect evaporative cooling system by placing direct evaporative cooling in first stage and indirect evaporative cooling in downstream and reported improvement in coefficient of performance by $20-25 \%$.

The developed two-stage system was evaluated for three different air velocities $(11.11,14.00$ and $16.70 \mathrm{~m} / \mathrm{s})$, three pad thicknesses (100, 150 and $200 \mathrm{~mm}$ ) and three water flow rates $(3,4$, and $5 \mathrm{lpm})$. For circulation of water in indirect system at the rate of 2.8 litre per minute and spraying of water over pad in direct system at water flow rates was maintained by necessary pvc piping, valves and a small water pump as shown in Figure 1. Indirect cooling system sensibly cooling process while direct cooling system is cooling and humidification process (adiabatic process). Entering air dry bulb temperature, wet bulb temperature and relative humidity data were collected at half an hour interval during the test period. Air velocity after indirect cooling system and direct cooling system were also measured. The data were analyzed with respect to effect of operating parameters on reduction in temperature, increase in relative humidity and drop in air velocity.

\section{CFD analysis}

Application of the CFD to analyze a fluid problem requires the following steps. First, the mathematical equations describing the fluid flow are written. These are usually a set of partial differential equations. These equations are then discretized to produce a numerical analogue of the equations. The domain is then divided into small grids or elements. Finally, the initial conditions and the boundary conditions of the specific problem are used to solve these equations. The solution method can be direct or iterative. In addition, certain control parameters are used to control the convergence, stability, and accuracy of the method. All CFD codes contain three main elements:

\section{a) Pre-processor \\ b) Flow solver and \\ c) Post-processor}

For CFD analysis virtual system has been modeled with solid works and analysis performed with flow simulation tool. The CFD model of experimental setup and evaporative cooling pad is shown in Figure 3.

\section{Results and Discussion}

\section{Effect of operating parameters on temperature drop}

The air leaving temperature after indirect cooling system was observed to be 29.75 \pm 1.92 . Also data indicate that the air temperature inside the storage chamberafter two-stage evaporative cooling (IDC/DEC) was recorded between 22.10 and $25.80^{\circ} \mathrm{C}$. From the temperature contours of CFD analysis the temperature after cooling pad is within the range of 22.67 to $26.04{ }^{\circ} \mathrm{C}$ as shown in (Fig. 4).

\section{Effect of operating parameters on RH inside storage chamber}

The performance of the developed experimental unit was also evaluated for the increase in relative humidity of the air inside the storage chamber. Outside air RH was 
calculated from dry bulb temperature and wet bulb temperature of ambient air, while inside the storage $\mathrm{RH}$ was measured using thermohygrometer (Frontier, humidity range:
$20 \%$ to $99 \%$ ). The, ambient (outside) average relative humidity was recorded between 30.46 and $46.72 \%$, whereas, inside average relative humidity observed from $40.50 \%$ to $72.83 \%$.

Fig.1 Experimental set-up of two-stage evaporative cooling system

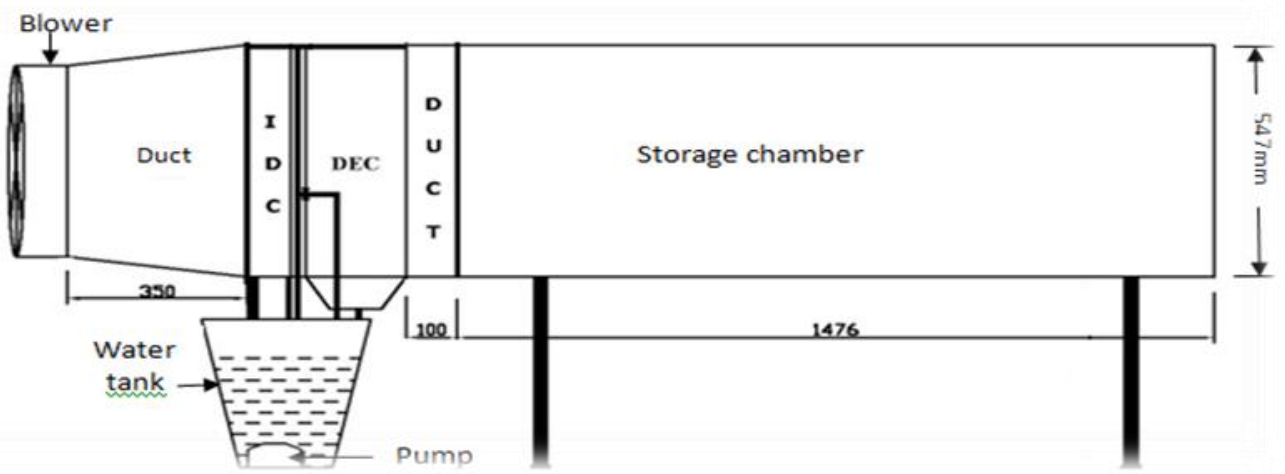

Fig.2 Fabricated two stage evaporative cooling system

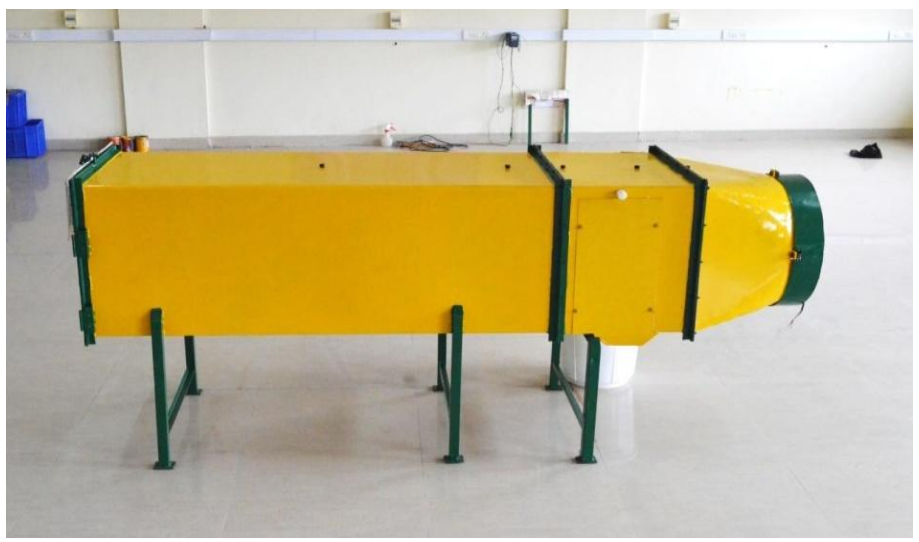

Fig.3 CFD model of experimental setup and Model of Evaporative cooling pad

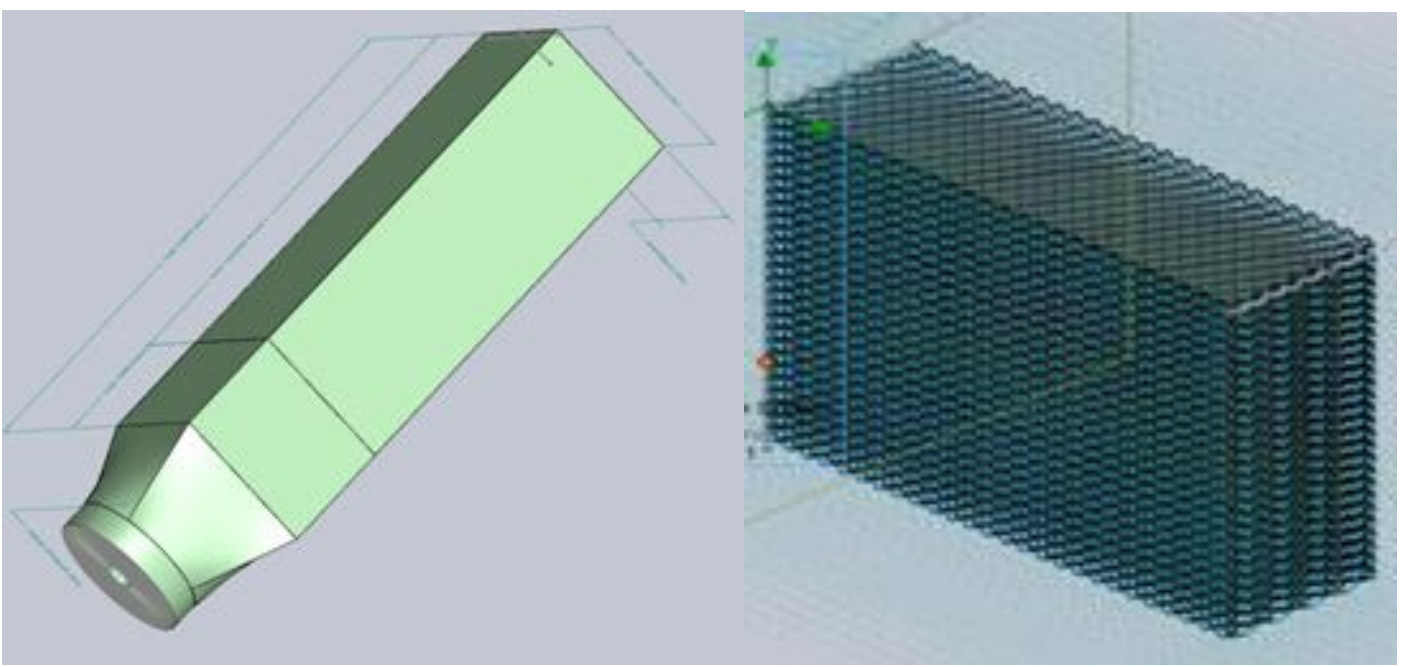


Fig.4 temperature contours at different points for cooling pad

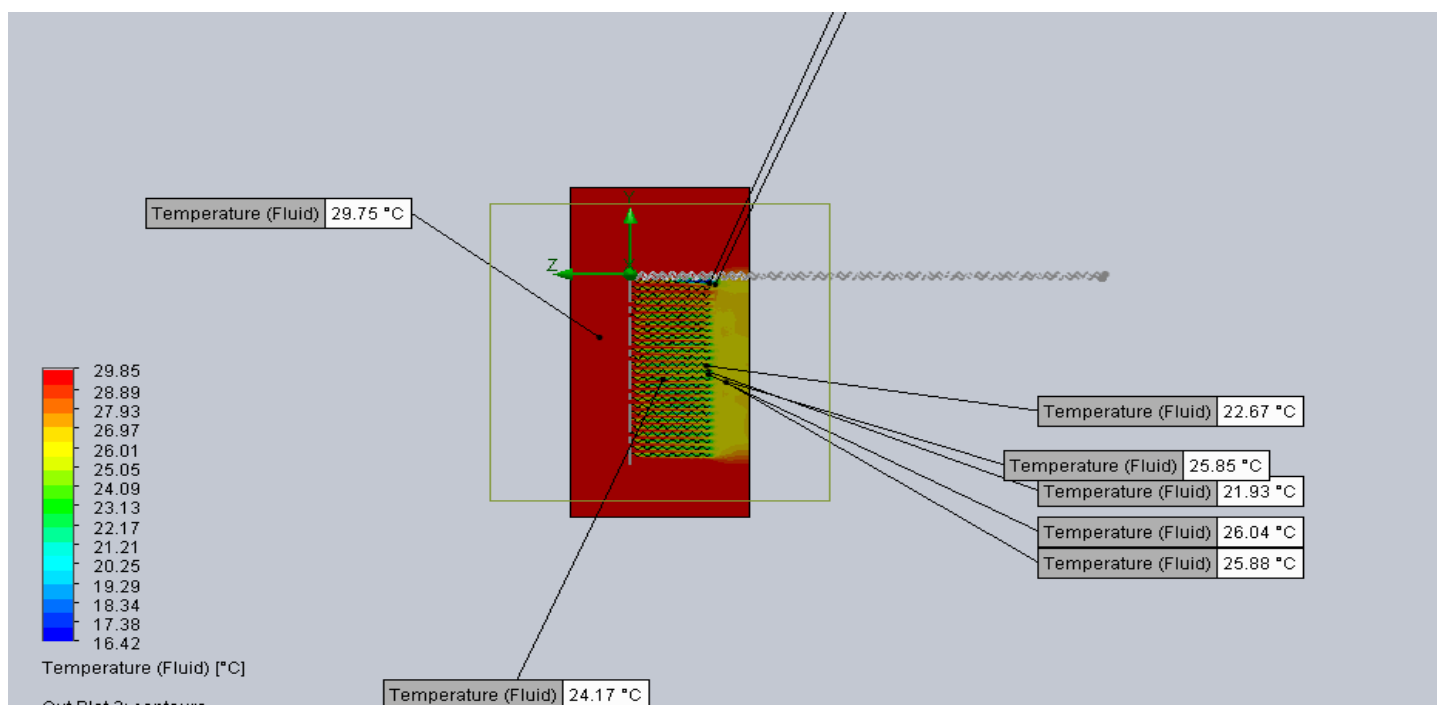

Fig.5 Relative humidity contours at different points for cooling pad

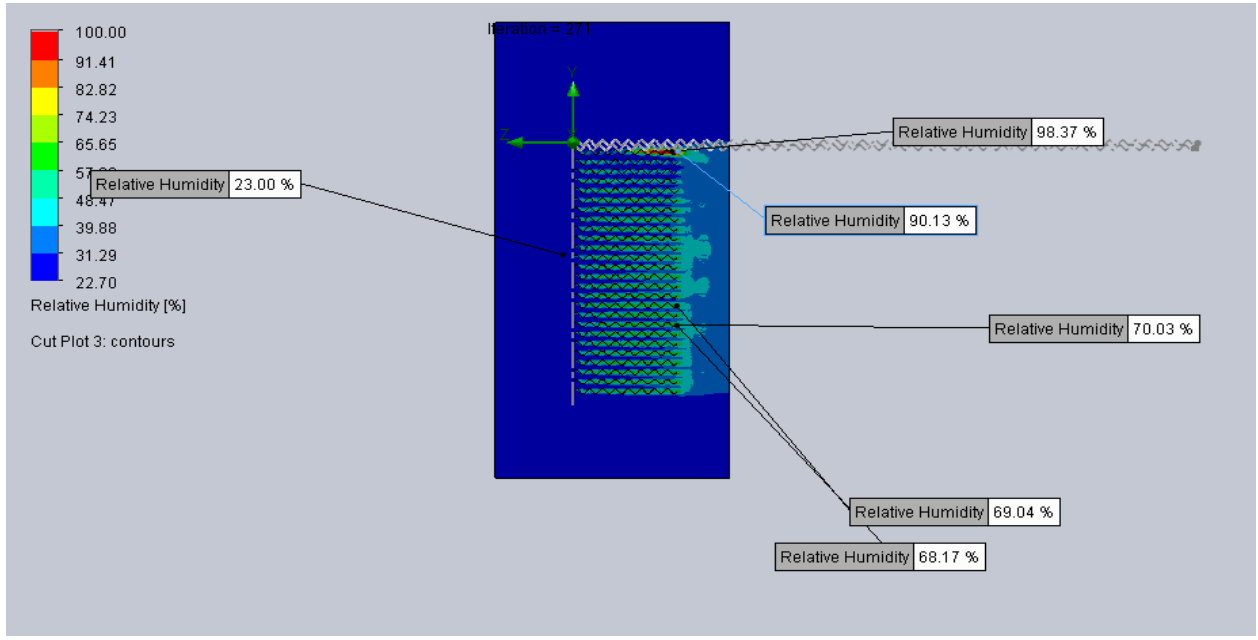

Fig.6 Velocity contour sat different points for cooling pad

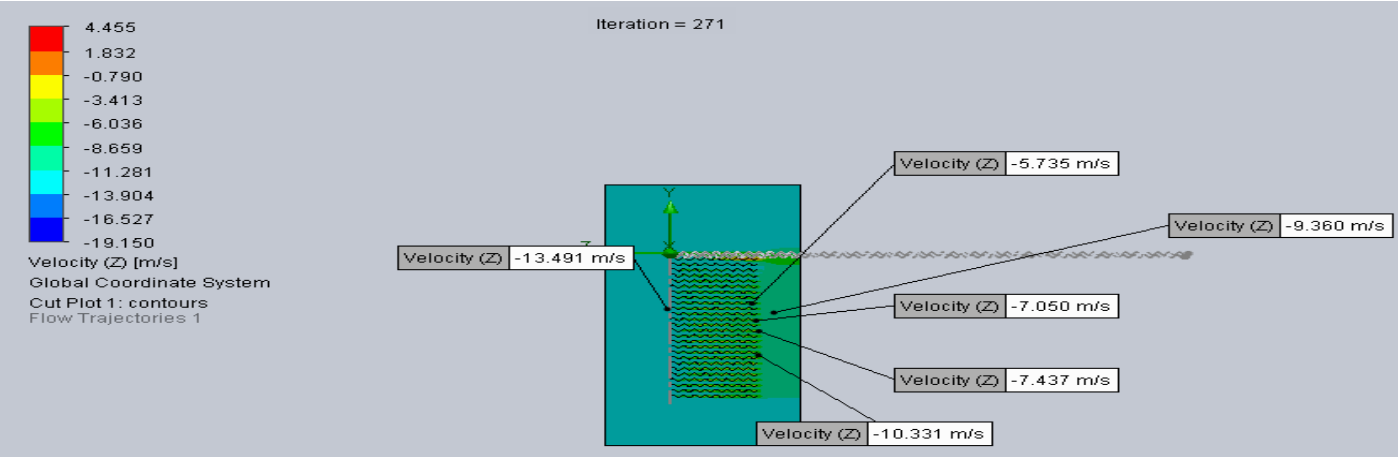


From the relative humiditycontours of CFD analysis the relative humidity after cooling pad is within the range of 39.88 to 74.22 as shown in Figure 5.

\section{Effect of operating parameters on drop in air velocity}

Velocity of air leaving the Indirect cooling (IDC) system and direct evaporative cooling (DEC) system was measured with hot wire anemometer. The leaving air velocity after IDC system recorded between $12.37 \mathrm{~m} / \mathrm{s}$ to $15.25 \mathrm{~m} / \mathrm{s}$ with supply air velocity of $16.7 \mathrm{~m} / \mathrm{s}$. Whereas leaving air velocity after DEC system was found to be varied from $12.10 \mathrm{~m} / \mathrm{s}$ to $14.90 \mathrm{~m} / \mathrm{s}$ for $16.7 \mathrm{~m} / \mathrm{s}$ air velocity respectively.

From the velocity contours of CFD analysis the velocity after direct cooling (DEC) system is within the range of 5.735-13.491 m/s (Fig. 6). Negative sign in Figure 6 indicates the negative $\mathrm{z}$ direction as per the model reference coordinate system.

In conclusion, the computational fluid dynamics analysis was carried using commercially available software SOLIDWORKS flow simulation to analyze the temperature distribution, relative humidity and velocity in the evaporative cooling system. An experimental study conducted on evaporative cooling system. Both CFD and Experimental results then compared. From the comparison, it has been observed that the CFD results are similar to the actual experimental results.

\section{References}

Anonymous. 2018. Introduction to computational fluid dynamics. Retrieved from http://www. mathematik.uni-dortmund.de/ kuzmin/ cfdintro/lecture1.pdf. [19 August.
2018].

Chakraverty, A., A. S. Mujumdar, G. S. Raghvan and Ramaswamy, H. S. 2003. Handbook of postharvest technology; cereals, fruits, vegetables, tea and spices. Marcel Dekker, Inc, New York.

Chaudhary, M. L. 2004. Recent developments in reducing postharvest losses in the Asia-Pacific region. Paper presented at the seminar on "reduction of postharvest losses of fruits and vegetables" held during Oct. 5-11 at New Delhi.

Chen, J., Y. Cai, F. Xu and Hu, H. Q. 2014. Analysis and Optimization of the FanPad Evaporative Cooling System for Greenhouse Based on CFD, Journal of Advances in Mechanical Engineering. 6: 712-740.

Sunmonu, M., K. J. Falua and David, A.O. 2014. Development of a low-cost refrigerator for fruits and vegetables storage. International Journal of Basic and Applied Science, 2(3):85-93.

Kumar, A., A. K. Gupta, B. S. Ghuman and Grover, L. 2003. Effectiveness of evaporatively cooled stores of various capacities constructed under different ambient conditions. Agricultural Engineering Today, Indian Society of Agricultural Engineers, 27(2-3):38-48.

Nitipong, S., and Sukum, K. 2011. Recycled high-density polyethylene and rice husk as a wetted pad in evaporative cooling system. American Journal of Applied Sciences, 8(2):186-191.

Mohmmad, A.K., 2013. Experimental performance evaluation of two-stage evaporative cooling system. Scholars Journal of Engineering and Technology, 1(3):122-127.

Li, H. X., Y. Wu, and Junmei. 2006. CFD Simulation and Analysis of the Combined Evaporative Cooling and Radiant Ceiling Air-conditioning System, HVAC Technologies for 
Energy Efficiency. 4(3).

Evaporative cooling by water spray systems: CFD simulation, experimental validation and sensitivity analysis, Building and Environment, 83: 129141.

Montazeria, H., B. Blockenab and Hensena, J. L. M. 2015.CFD analysis of the impact of physical parameters on evaporative cooling by a mist spray system, Applied Thermal Engineering.75: 608-622.

Sapounas, A., C. H. Nikita-Martzopoulou and Martzopoulos, G. 2008. Numerical and Experimental Study of Fan and Pad Evaporative Cooling System in a Greenhouse with Tomato Crop. Quelle, Acta Horticulturae. 987 - 994.

\section{How to cite this article:}

Vala, K.V., Mahesh Makwana and Nukasani Sagarika. 2019. Validation of Evaporative Cooling System using CFD Analysis. Int.J.Curr.Microbiol.App.Sci. 8(03): 393-399. doi: https://doi.org/10.20546/ijcmas.2019.803.049 